\title{
Characterization and Visualization of Voltage Dips in Wind Power Installations
}

\author{
Emilio Gómez-Lázaro, Juan Alvaro Fuentes, Angel Molina-García, and Miguel Cañas-Carretón
}

\begin{abstract}
The purpose of this paper is to describe and assess a new characterization and classification method of voltage dips. The proposed method allows us to classify multistage and real voltage dips when measurement errors or transients are present in the recorded data. Different real voltage dips are used to assess this method, comparing the results with previous approaches. For visualization purposes, a voltage-space vector representation is introduced in order to clarify the global voltage dip evolution along the time. The classification of all the voltage dips, measured from a one-year field measurement campaign in wind farms located in the Spanish region of Castilla-La Mancha, is also presented and characterized according to the proposed method.
\end{abstract}

Index Terms-Power quality (PQ), voltage dip, wind power generation.

\section{INTRODUCTION}

V OLTAGE dips are one of the power-quality (PQ)-related aspects affecting sensitive loads in the industrial sector [1]. A voltage dip is defined as a sudden reduction-between $10 \%$ and $90 \%$ - of the voltage at a point in the electrical system, which lasts from a half cycle to $1 \mathrm{~min}$ [2]. This is becoming more important as a consequence of the PQ requirements imposed by sophisticated electrical and electronic equipment—due to their vulnerability to voltage dips—such as computers, programmable logic controllers, and variable speed drives. This equipment can normally be tripped when the voltage drops below $90 \%$ of the rated voltage over a few cycles [1], [3]. Voltage dips affect wind farms as well; wind turbines were disconnected from the grid when the terminal voltage fell below $80 \%-90 \%$ [4], [5] until the imposition of new requirements [6]-[9]. Even relays and contacts in the starter motor can be sensitive to voltage dips, resulting in the shutdown of a process when they drop out [10].

Voltage dips are mainly due to short circuits and earth faults in the grid [11]. These faults in the power system, which may be far away from the location of the wind farm or any other

Manuscript received April 11, 2008; revised February 18, 2009. Current version published September 23, 2009. This work was supported in part by the "Ministerio de Educación y Ciencia"-ENE2006-15422-C02-01/ALT, in part by ENE2006-15422-C02-02/ALT-, and in part by "Junta de Comunidades de Castilla-La Mancha" (PAI08-0145-9976). Paper no. TPWRD-00237-2008.

E. Gómez-Lázaro and M. Cañas-Carretón are with the Renewable Energy Research Institute and the Department of Electrical, Electronic, and Control Engineering, EPSA. Universidad de Castilla-La Mancha, Albacete 02071, Spain (e-mail: emilio.gomez@uclm.es; miguel.canas@uclm.es).

J. A. Fuentes and A. Molina-García are with the Department of Electrical Engineering, Universidad Politécnica de Cartagena, Cartagena 30202, Spain (e-mail: juanalvaro.fuentes@upct.es; angel.molina@upct.es).

Color versions of one or more of the figures in this paper are available online at http://ieeexplore.ieee.org.

Digital Object Identifier 10.1109/TPWRD.2009.2027513 power installation, can produce a voltage dip at the connection point of the wind turbines. Factors governing the magnitude and duration of voltage dips include the fault type, fault impedance and location, the configuration of the electrical network, and the protective relay system. This last aspect is very important, since voltage dip conditions last until the fault is cleared by a protective device, with the fault clearing time being dependent on the utility protection practices-instantaneous fault clearing or intentional time delay fault clearing. Solutions for the effects of voltage dips must be implemented at the end customer since it is impossible to eliminate faults in the power system, although it is possible for the utility to reduce the number and the effects of faults through design practices and specific equipment [10].

The economic issues related to the impact of voltage dips in power systems are also important [12]. These disturbances involve costs that have to be taken into account, such as lost production or damage to equipment. Obviously, the economic impact depends on the equipment sensitivity, system voltage dip characteristics, and the economic value of the affected wind farms. IEEE 1346-1998 provides some guidelines for calculating the costs produced by electrical disturbances in power energy systems [13].

These days, wind farm penetration in power systems is constantly increasing. Therefore, some national grid codeswhich are specified by the Transmission System Operators (TSOs) — have additional requirements for integrating wind power installations with conventional types of generation, since premature tripping of wind generators due to power system disturbances can put system stability at risk, contributing to amplifying the disturbance [11], [14]. Specifically, national grid codes require uninterrupted generation throughout power system disturbances, support of the network voltage and frequency, and, therefore, extending characteristics, such as lowvoltage ridethrough and reactive and active power capabilities [15], [16]. Therefore, national grid codes demand, or impose, low-voltage ridethrough capability on wind farms and wind turbines. For this reason, manufacturers are supplying this capability, which is becoming standard in modern wind turbines.

However, national grid codes impose different requirements according to their electrical network configuration and protective relay system. In [16]-[19], grid connection requirements for Spain, Denmark, Germany, Ireland, Sweden, and Scotland are studied. As a result, and due to the importance of voltage dips in power system as well as in the integration of wind energy, detailed studies of voltage dip classification and characterization are gaining importance. In this context, a new approach using voltage dip visualization and characterization is presented by the authors, demonstrating its characteristics and comparing it to previous classification methodologies. 


\section{Voltage Dip Characterization. StATE OF THE ART}

Voltage dip characterization concerns the quantification of voltage-dip events through a limited number of parameters [20]. These parameters depend on the field of study; it could be as reduced as the magnitude (or "remaining voltage") and duration, or as broad as the measured voltage of all three phases. In the field of wind generation, voltage dip asymmetry is of interest, and the relation between the negative- and positive-sequence voltages quantifies this asymmetry. Indeed, most methods for characterizing voltage dips use two parameters to determine the severity of a voltage dip: magnitude (or "remaining voltage") and duration.

However, voltage dips can be far more complicated than this type of characterization shows, since these methods are usually based on the lowest remaining voltage and the longest duration of all three voltages [3], [21]-[23]. This simplification is adequate for a three-phase voltage dip, but not for other voltage dip types as, for example, a phase-to-phase one. Therefore, it is an appropriate approximation for balanced dips, but not for unbalanced dips [22], the most usual voltage dip type. For this reason, some authors propose different methods to characterize unbalanced dips, being based on measurements or considering simplified electrical models [20]. Other authors consider that additional voltage dip information can be relevant, such as the dip depth and the phase-angle jump along with start and end times [21], or the individual phase voltages during the disturbance [24]. Besides, these simplified methodologies are not adequate for multistage voltage dips in which the fault can evolve from one type to another. Finally, the voltage profile is usually modeled during the voltage dip as a rectangular shape. Therefore, nonrectangular dips are overestimated [3], [20]. This can be important in many industrial customers, with large induction motor loads, or in wind farms.

Basically, the input data to the characterization methods can be fitted in:

- monitoring the lowest remaining voltage and the longest duration of all the three voltages, as previously commented;

- monitoring all of the voltage waveforms with an adequate sample rate;

- monitoring of $\sqrt{V_{d}^{2}+V_{q}^{2}}$ in a vector controller [1]; this method is derived from the space vector control usually used in the control of induction machines; the three-phase voltages are converted into one phasor with two orthogonal components and synchronous reference frame, which is locked via a phase-locked loop (PLL).

In [21], two methods to obtain three-phase voltage dip characterization-ABC classification and symmetrical components classification - are described and compared. It is concluded that ABC classification-due to its simplicity-is more often used than the symmetrical components, being also more intuitive and giving a good approximation about the evolution of the dips along the different voltage levels of the network. The ABC classification should not be considered as a different classification, since it is a special case of the symmetrical components classification. However, this classification is based on a simplified model of the network, being not recommended in [21] for the classification of voltage dips obtained from measured instantaneous voltages. The ABC classification considers seven types of voltage dips, by defining complex voltages and phasor diagrams based on the relations between the minimum phase-to-neutral voltage $V_{\mathrm{PN}}$ and the minimum phase-to-phase voltage $V_{\mathrm{PP}}$.

- Type A: All phases experience the same remaining voltage and phase-angle jump

$$
V_{\mathrm{PP}}=V_{\mathrm{PN}}
$$

- Type B: It is not very common, since it appears when a line-to-ground fault occurs at the same voltage level or at a location connected by a wye-wye transformer grounded at both sides

$$
V_{\mathrm{PP}}=\frac{\sqrt{\left(\frac{1}{2}+V_{\mathrm{PN}}\right)^{2}+\frac{3}{4}}}{\sqrt{3}} .
$$

- Type $\mathrm{C}$ : It is a reduction of the voltage in two phases. It is caused by a line-to-line fault or by a propagation of type B dip through a delta-wye-connected transformer

$$
V_{\mathrm{PP}}^{2}=\frac{4}{3} V_{\mathrm{PN}}^{2}-\frac{1}{3} \text {. }
$$

- Type D: It is caused by the propagation of a type C dip through a delta-wye winding connected transformer. It is a voltage drop in one phase

$$
V_{\mathrm{PP}}^{2}=\frac{1}{4}+\frac{3}{4} V_{\mathrm{PN}}^{2} .
$$

- Type E: It shows a symmetrical relation between PP and PN voltage, similar to type A. This dip is rare, as type B, by the same reasons.

- Type F: It is a reduction of the voltage in one phase, caused by the propagation of a line-to-line-to-ground fault through a delta-wye-connected transformer

$$
3 V_{\mathrm{PP}}^{2}=\left(2+\frac{1}{3}\right) V_{\mathrm{PN}}^{2}+\frac{1}{3} V_{\mathrm{PN}}+\frac{1}{3} .
$$

- Type G: These dips are obtained from the propagation of a type F dip through a delta-wye-connected transformer[21]

$$
V_{\mathrm{PP}}=-0.0707+\frac{\sqrt{3.112 V_{\mathrm{PN}}^{2}-0.327}}{1.556} .
$$

Finally, in [25], theoretical relations between the minimum phase-to-neutral voltage $V_{\mathrm{PN}}$ and the minimum phase-to-phase voltage $V_{\mathrm{PP}}$ are graphically presented and discussed. Nevertheless, real monitoring results are more dispersed from the theoretical curves than the simulation results, and they do not usually satisfy the previous relations. In this context, this paper describes and assesses a new characterization and classification method of voltage dips according to the previous approaches.

\section{Proposed Voltage Dip Characterization AND VISUALIZATION}

\section{A. Introduction}

Voltage dips are important in wind power, since their characteristics and density are taken into account in the definition of national grid codes. However, not much information is available about voltage dip surveys in national power systems [26]. On the other hand, wind turbine designs must support the voltage dips defined in the national grid codes. Therefore, and due to 
TABLE I

EXAMPLE OF THE $V_{\mathrm{PP}}$ AND $V_{\mathrm{PN}}$ SELECTION

\begin{tabular}{|c|c|c|c|c|c|c|c|c|c|c|c|c|}
\hline & \multicolumn{3}{|c|}{$V_{P P}(p u)$} & \multicolumn{3}{|c|}{$\min \left\{V_{P P}(p u)\right\}$} & \multicolumn{3}{|c|}{$V_{P N}(p u)$} & \multicolumn{3}{|c|}{$\min \left\{V_{P N}(p u)\right.$} \\
\hline Time & $\mathrm{AB}$ & $\mathrm{BC}$ & $\mathrm{CA}$ & $\mathrm{AB}$ & $\mathrm{BC}$ & $\mathrm{CA}$ & A & B & $\mathrm{C}$ & A & $\mathrm{B}$ & $\mathrm{C}$ \\
\hline 0 & 0.9660 & 1.0010 & 0.9440 & $\mathbf{x}$ & - & - & 0.9288 & 0.9526 & 0.9690 & $\mathbf{X}$ & - & - \\
\hline$\Delta t$ & 0.8966 & 0.9916 & 0.7636 & - & - & $\mathbf{x}$ & 0.8732 & 0.9205 & 0.9143 & $\mathbf{x}$ & - & - \\
\hline $2 \Delta t$ & 0.6866 & 0.9596 & 0.6766 & - & - & $\mathbf{x}$ & 0.6032 & 0.8805 & 0.8964 & $\mathbf{x}$ & - & - \\
\hline $3 \Delta t$ & 0.6787 & 0.9296 & 0.6263 & - & - & $\mathbf{x}$ & 0.5297 & 0.8675 & 0.8271 & $\mathbf{x}$ & - & - \\
\hline $4 \Delta t$ & 0.6193 & 0.8783 & 0.6041 & - & - & $\mathbf{x}$ & 0.4918 & 0.8052 & 0.7935 & $\mathbf{x}$ & - & - \\
\hline $5 \Delta t$ & 0.6055 & 0.8521 & 0.5831 & - & - & $\mathbf{x}$ & 0.4807 & 0.7858 & 0.7790 & $\mathbf{x}$ & - & - \\
\hline $6 \Delta t$ & 0.6286 & 0.8469 & 0.6549 & $\mathbf{x}$ & - & - & 0.5570 & 0.7737 & 0.7952 & $\mathbf{x}$ & - & - \\
\hline $7 \Delta t$ & 0.8771 & 0.8753 & 0.8674 & - & - & $\mathbf{x}$ & 0.8712 & 0.8790 & 0.8694 & - & - & $\mathbf{x}$ \\
\hline $8 \Delta t$ & 0.8864 & 0.8934 & 0.8835 & - & - & $\mathbf{x}$ & 0.8821 & 0.8920 & 0.8891 & $\mathbf{x}$ & - & - \\
\hline $9 \Delta t$ & 0.9113 & 0.9272 & 0.9149 & $\mathbf{x}$ & - & - & 0.9084 & 0.9207 & 0.9243 & $\mathbf{x}$ & - & - \\
\hline & & & & 3 & 0 & 5 & & & & 7 & 0 & 1 \\
\hline
\end{tabular}

the importance of voltage dips in the integration of wind energy into the power system, detailed studies of voltage dip statistics and characterization are gaining importance. To gather this information, a voltage dip survey in wind farms located in the Spanish region of Castilla-La Mancha-the second largest region in Spain in terms of installed wind power with $3131 \mathrm{MW}$ as of January 2008 [27] — is being conducted by the authors.

Voltage dips obtained from this survey were classified by using previous characterization methods. The symmetrical component classification method was applied but, due to a small error in frequency which may result in an erroneous dip type [20], inadequate results were obtained. The methodology based on [25] was also implemented and showed better results than the former, but because of it, only uses the absolute minimum $V_{\mathrm{PP}}$ and $V_{\mathrm{PN}}$ values and it presents drawbacks as follows.

- Real voltage dips can present measurement errors or transients due to the activation of the protective relay system and, then, they do not exactly satisfy the expressions from (1)-(6). This fact is also mentioned in [25]. Besides, the authors have checked that up to $90 \%$ of the points corresponding to real voltage dips present distance relative errors higher than $25 \%$ to these theoretical curves.

- Multistage voltage dips are not identified, since only one point is obtained for each voltage dip and, therefore, only one type can be identified in each case.

- The absolute minimum values of $V_{\mathrm{PP}}$ and $V_{\mathrm{PN}}$ phasors are not relevant enough for describing the average severity of a dip, in terms of the reduction of voltage along the time interval.

To overcome these limitations, an extension of the ABC classification method by defining areas linked to each of the voltage dip types is proposed (see Fig. 1). These regions-distinguished by different colours - are defined by using the minimum distance of $\left(V_{\mathrm{PN}}, V_{\mathrm{PP}}\right)$ points to each theoretical curve. Additionally, to characterize multistage voltage dips, a full representation along the voltage dip time interval of the $V_{\mathrm{PN}}$ and $V_{\mathrm{PP}}$ values is also analyzed.

\section{B. Description of the Characterization Process}

In accordance with the previous paragraph, the proposed characterization is based on the instantaneous voltage data collected before, during, and after the voltage dip. From these data, the fast Fourier transform (FFT) is applied in order to

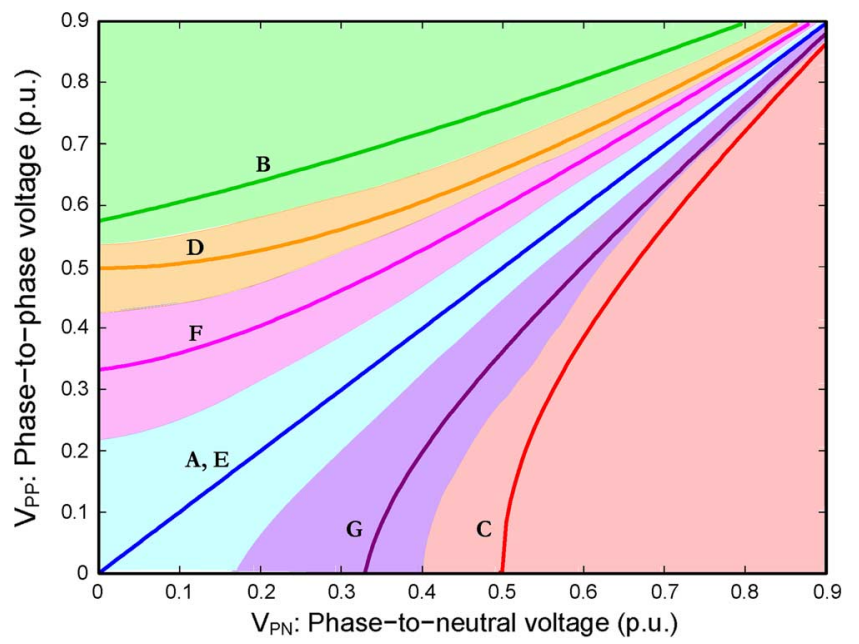

Fig. 1. Proposed extension of the ABC method: classification areas.

obtain the values of $V_{\mathrm{PP}}$ and $V_{\mathrm{PN}}$ over the voltage dip time interval by using a sliding window technique with a $\Delta t$ size that depends on the power system frequency. Thus, for each $\Delta t$, a set of three $V_{\mathrm{PP}}$ and three $V_{\mathrm{PN}}$ voltage phasors-which correspond with the fundamental harmonics of the Fourier decomposition analysis - is obtained and compared, selecting from each set of three $V_{\mathrm{PP}}$ and $V_{\mathrm{PN}}$ the minimum values in each case. Therefore, two vectors of $V_{\mathrm{PP}}$ and $V_{\mathrm{PN}}$ minimum values are built, storing at the same time for each $\Delta t$ those phases, in case of $V_{\mathrm{PP}}$, or phase, in case of $V_{\mathrm{PN}}$, where the minimum values are measured. In this way, Table I shows an example of $V_{\mathrm{PP}}$ and $V_{\mathrm{PN}}$ data as well as the phase-to-phase $\mathrm{CA}$ and phase-to-neutral A voltage selected, which corresponds to the representative voltages of the dip: phase-to-phase and phase-to-neutral voltage phasors in which the maximum frequency of minimum values is given. Once selected, these representative voltages are plotted in an XY diagram of $V_{\mathrm{PP}}$ and $V_{\mathrm{PN}}$ values (see Fig. 2), where the point corresponding to $t=2 \Delta t$ has been highlighted. Then, these points correspond to the representative voltages, and show the voltage dip evolution over time.

From the previous XY diagram, the classification process continues, obtaining the region to which each pair of $V_{\mathrm{PP}}$ and $V_{\mathrm{PN}}$ points belongs to. Following this, the frequencies corresponding to each region are obtained-region clustering (see 


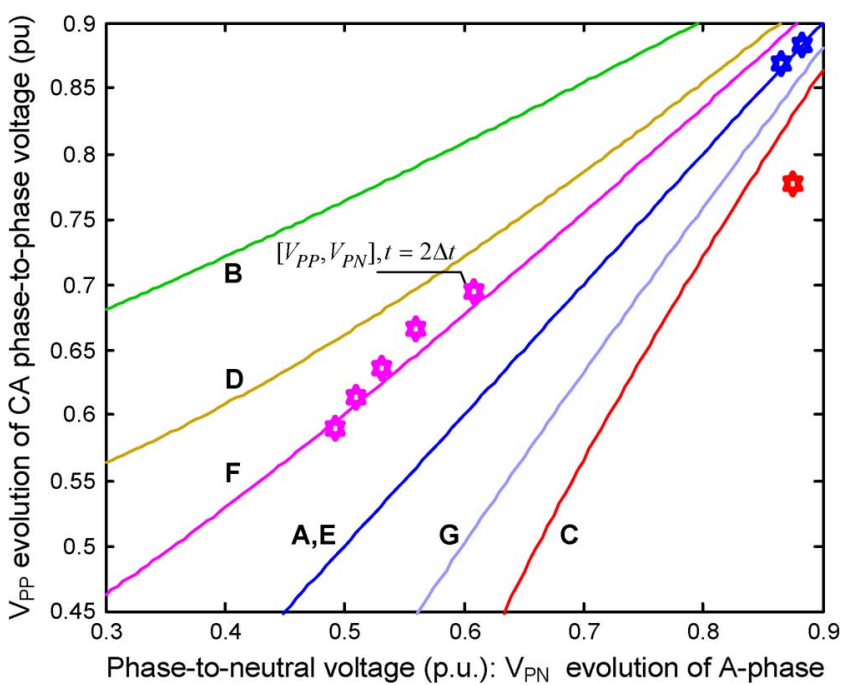

Fig. 2. $V_{\mathrm{PP}}$ and $V_{\mathrm{PN}}$ evolution. Example.

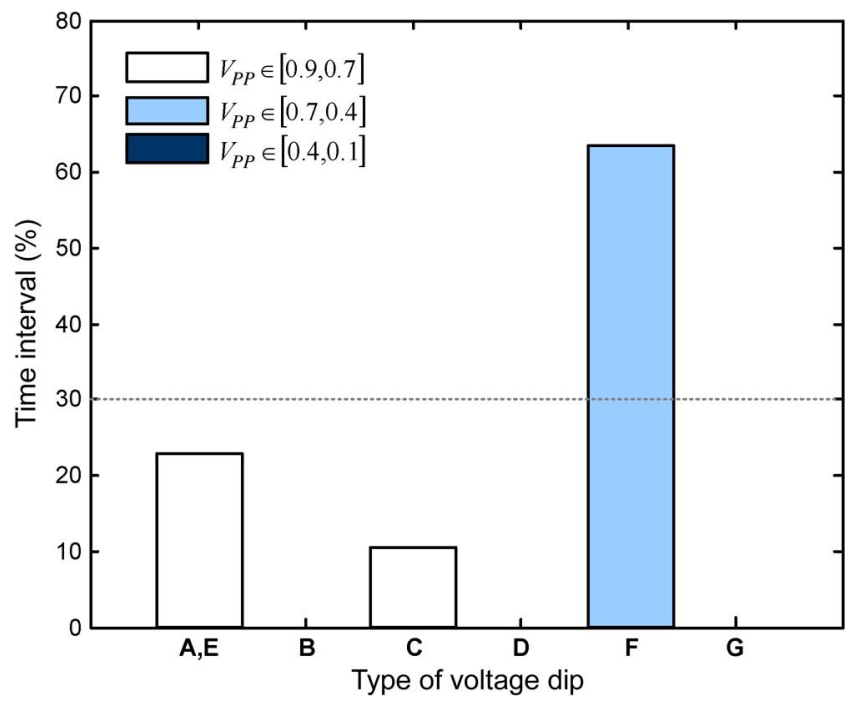

Fig. 3. Region clustering. Example.

Fig. 3) and compared. Then, the voltage dip is classified in accordance to those regions whose relative frequencies exceed a given threshold-in this example, the region corresponding to Type F. Therefore, multistage voltage dips, where the behavior corresponds to more than one theoretical characterization, can also be classified. In addition, the average severity of the dip is also taken into account since this information is considered for the characterization process-voltage dip classification (see Fig. 4). This last step summarizes the global information of the voltage dip: type(s) of dip: severity and time. Finally, Fig. 4 shows a general scheme of the proposed characterization process, comparing the stages with previous approaches.

For visualization purposes, in addition to the aforementioned $V_{\mathrm{PP}}$ and $V_{\mathrm{PN}}$ representation in Fig. 1, an alternative voltage dip representation, which also retains the information on the threephase voltage magnitudes, is also proposed and assessed. This graphical representation is based on the voltage space phasor [28], which helps us to visualize, in a single figure, the evolution along the time of the voltage dip as is shown in the next section.

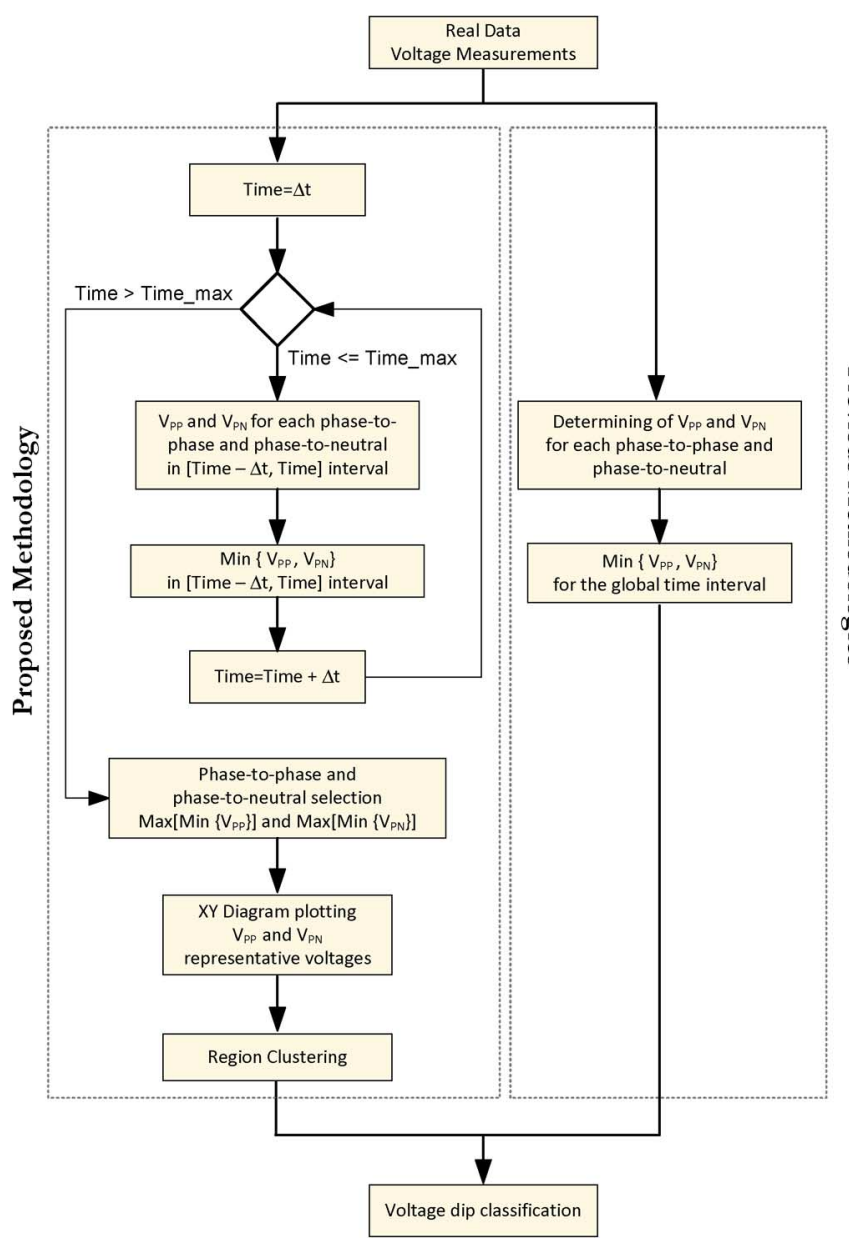

Fig. 4. Proposed classification method. General scheme.

\section{RESULTS}

Two PQ analyzers-fulfilling IEC 61000-4-30 class A accuracy, frequency synchronization, and absolute time requirements-have been installed in a Spanish wind farm, being part of a voltage dip survey carried out by the authors. These analyzers, with a $10.25-\mathrm{kHz}$ sample rate per channel, are able to capture detailed voltage and current waveforms during the voltage dip and the clearance of the fault, together with powerful trigger options to obtain the entire transient. In [29], a detailed installation scheme of both PQ analyzers is provided. One of them is located at the wind turbine nacelle-Gamesa G90 2.0 MW - between the doubly-fed induction generator (DFIG) and the $0.69 / 20-\mathrm{kV}$ power transformer. This PQ analyzer measures three stator voltages and currents, together with a rotor line current and the dc bus voltage in the rotor power converter. The other PQ analyzer is located at the wind farm electrical substation.

The evolution of the three-phase voltages along the dip and during the clearance of the fault have been studied and presented in the following subsections, comparing the results obtained by using [25] $V_{\mathrm{PN}}$ and $V_{\mathrm{PP}}$ absolute minimum method and the characterization and identification of the proposed method. The voltage dip examples are:

- a phase-to-phase voltage dip, becoming a three-phase voltage dip during the final stage; 
- a three-phase voltage dip at the beginning of the fault, which evolves to a phase-to-phase voltage dip during the rest of the fault.

Finally, the classification of all voltage dips measured from a one-year field measurement campaign in wind farms located in the Spanish region of Castilla-La Mancha is also presented and characterized according to the proposed method.

\section{A. Example (I)}

As can be seen in Fig. 5, the voltage dip starts as a phase-to-phase voltage dip and during the short last stage, it becomes a three-phase voltage dip. According to the characterization process, $V_{\mathrm{PP}}$ and $V_{\mathrm{PN}}$ values for each phase-to-phase and phase-to-neutral voltages are determined by using a $\Delta t$ of $20 \mathrm{~ms}$-in order to select the representative voltages. In this case, $\mathrm{AC}$ and $\mathrm{A}$ voltages present the highest number of minimum values and, therefore, $V_{\mathrm{PP}}$ and $V_{\mathrm{PN}}$ are $V_{\mathrm{AC}}$ and $V_{\mathrm{AN}}$ for the following stage of the characterization process. In Fig. 5(b), the evolution of the voltage dip is shown in a $V_{\mathrm{PP}}$ and $V_{\mathrm{PN}}$ diagram and, in Fig. 5(c), the region clustering step is presented by using a color code to include the severity of the voltage dip. Then, this figure includes information about the severity, the regions, and the percentage of the voltage dip time interval, since each $V_{\mathrm{PP}}$ and $V_{\mathrm{PN}}$ point is obtained for each $\Delta t$. Therefore, this representation gives us a summarized information of the voltage dip. Using a threshold to remove the less important data, Fig. 5(d) shows the results in a $V_{\mathrm{PP}}$ and $V_{\mathrm{PN}}$ diagram, comparing this classification with the $V_{\mathrm{PP}}$ and $V_{\mathrm{PN}}$ absolute minimum method. Thus, the global evolution of the voltage dip is correctly identified by using the proposed method, while the $V_{\mathrm{PP}}$ and $V_{\mathrm{PN}}$ absolute minimum method classifies it only as a phase-to-phase voltage dip, neglecting the final time interval of the dip - around $40 \%$ of the dip time - and classifying the dip with higher severity than its real evolution.

Additionally, Fig. 6 shows the polar Fig. 6(b) and cylindrical Fig. 6(a) representation of the voltage space vector, where the $Z$-axis corresponds to the time, in Fig. 6(a). At the beginning of the voltage dip, the voltage space vector is an ellipse, which corresponds to a phase-to-phase fault where its major axis is aligned with the nonfaulted phase voltage. Later, it evolves following the typical circumferences of a three-phase voltage dip and, finally, the voltage space vector recovers its nominal value. Therefore, this visualization helps to classify and identify the voltage dip.

\section{B. Example (II)}

Fig. 7 shows a clear case of a multistage voltage dip. In Fig. 7(a), it can be seen how, at the beginning, the three voltage phases drop significantly in a similar way-typical of a three-phase voltage dip, and during the rest of the time interval, two phases are practically recovered while the other one-phase B-takes more time-typical of an asymmetrical fault. In Fig. $7(\mathrm{~b})$, the $V_{\mathrm{PP}}$ and $V_{\mathrm{PN}}$ values are selected as representative of the voltage dip-in this case, $V_{\mathrm{AB}}$ and $V_{\mathrm{BN}}$ are shown, where the trajectory along the time of the selected $V_{\mathrm{PP}}$ and $V_{\mathrm{PN}}$ minimum values cross over several regions. Following a similar structure than in the previous case, Fig. 7(c)

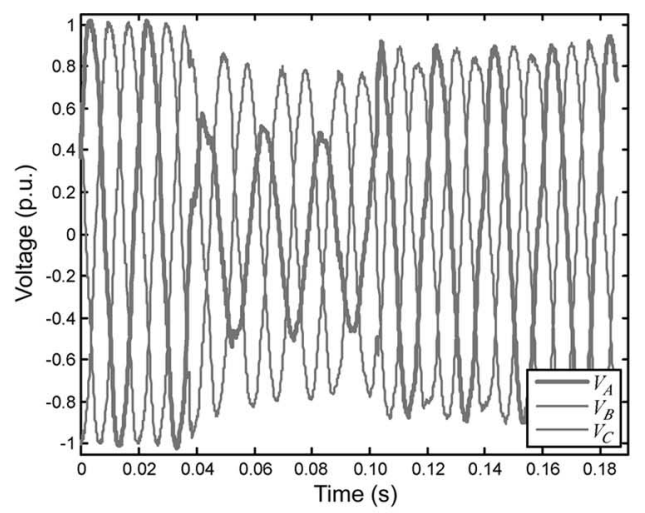

(a)

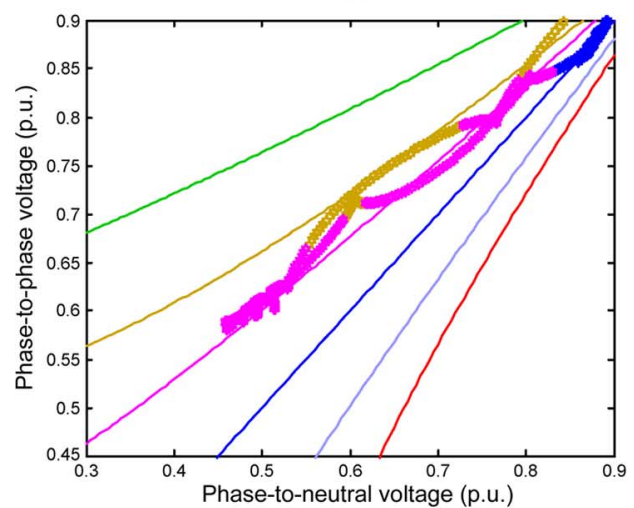

(b)

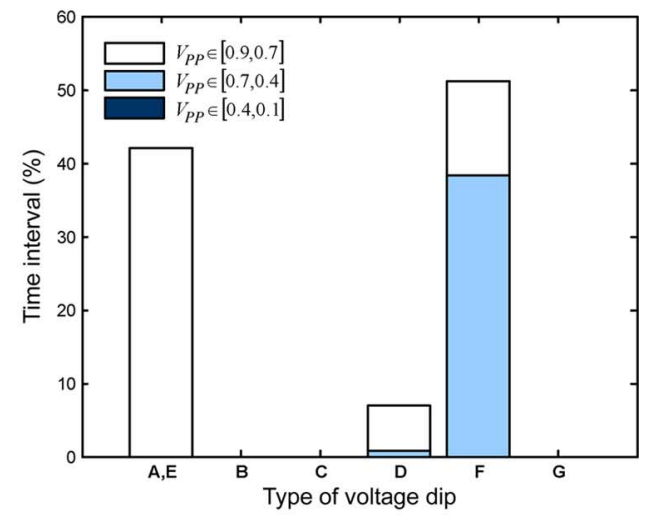

(c)

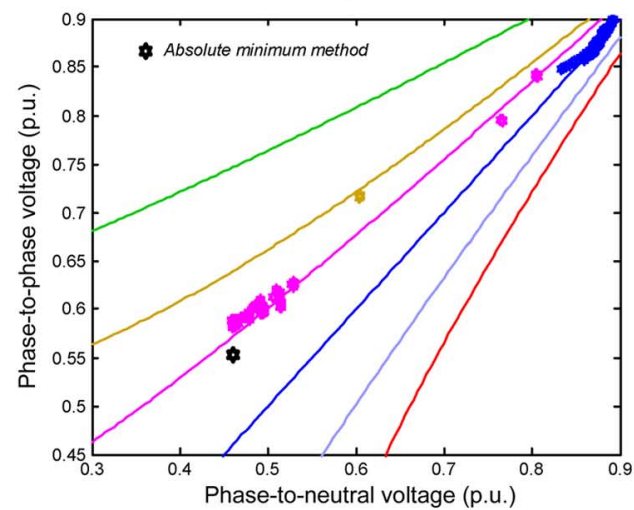

(d)

Fig. 5. Example (I). Characterization and comparison of methods. (a) Instantaneous voltage waveforms. (b) $V_{\mathrm{PP}}$ and $V_{\mathrm{PN}}$ evolution. (c) Region clustering. (d) Comparison of voltage dip classification.

presents the region clustering step, using a bar diagram with a color code to include the severity of the voltage dip in each 


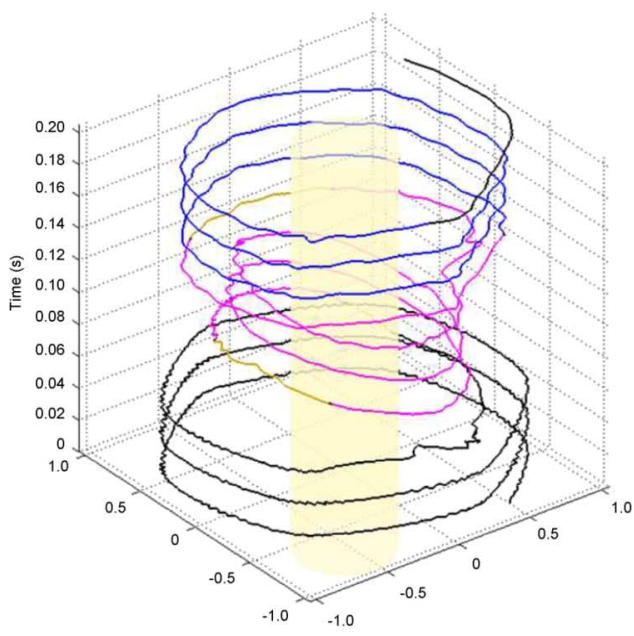

(a)

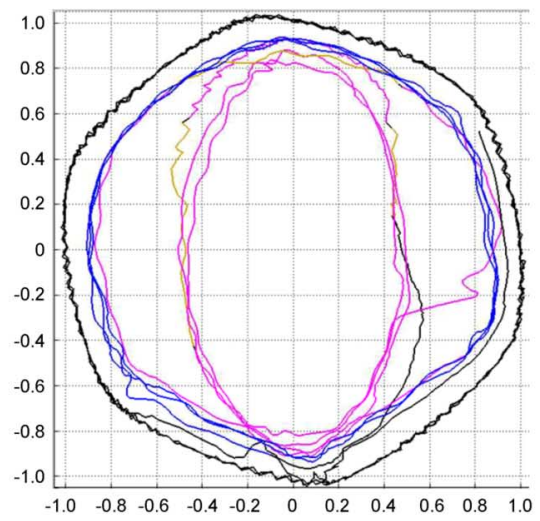

(b)

Fig. 6. Example (I). Visualization of the voltage dip. (a) Cylindrical representation. (b) Polar representation.

region. Finally, Fig. 7(d) compares both classification methods. The proposed method correctly identifies the voltage dip as a three-phase voltage dip-AE type-which later evolves toward a phase-to-phase voltage dip-F type. However, the $V_{\mathrm{PP}}$ and $V_{\mathrm{PN}}$ minimum absolute method classify this voltage dip as only a three-phase voltage dip type, even though the majority of the time interval is a phase-to-phase voltage dip.

In a similar way as the previous case, Figs. 8 and 9 show a cylindrical and polar representation, respectively, of the voltage space vector, where the circumferences corresponding to the three-phase faults and the ellipse shape-typical of the asymmetrical faults - can be identified, before recovering the nominal voltage. Thus, a 3-D representation is presented in Fig. 8, where the $z$ axis corresponds to time. In order to make this trajectory clearer, it has been divided into two stages which are presented in Fig. 8(b) and (c).

\section{Voltage Dip Classification. Global Results}

Fig. 10 shows a classification of all the voltage dips that have been measured during a one-year field measurement campaign in wind farms located in the Spanish region of Castilla-La Mancha, where the regions with a high density of $V_{\mathrm{PP}}$ and $V_{\mathrm{PN}}$ values corresponding to each voltage dip have been highlighted. As can be seen in this figure, the multistage voltage dips are undoubtedly well classified, being linked with a black dashed

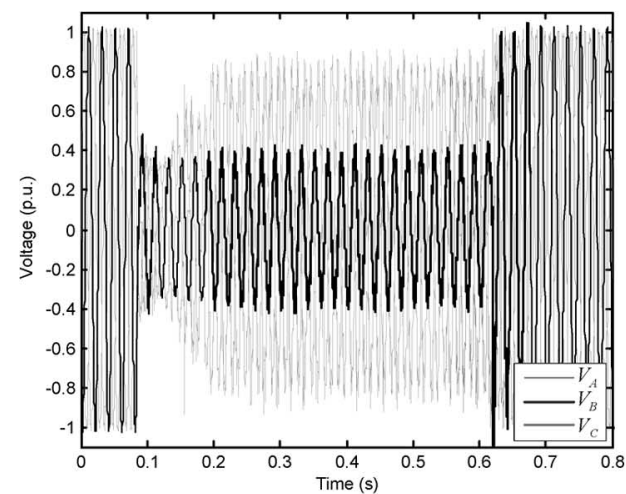

(a)

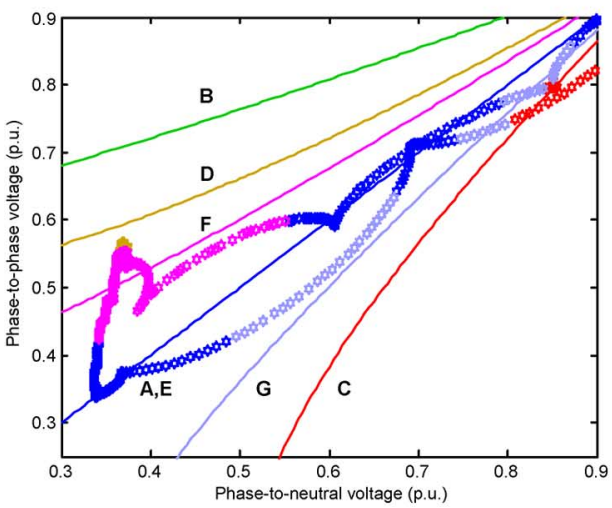

(b)

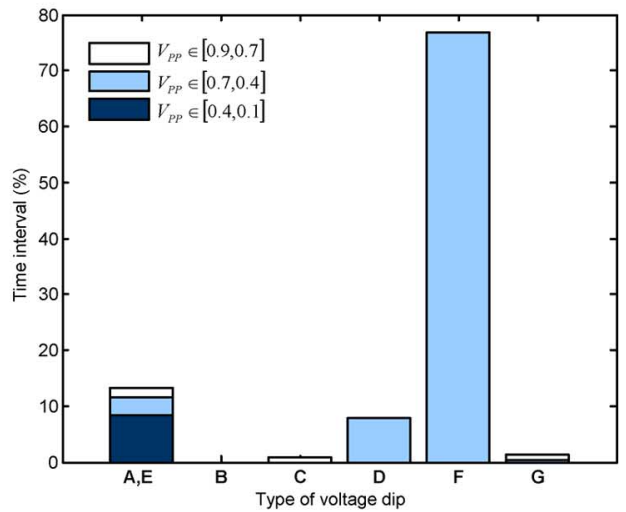

(c)

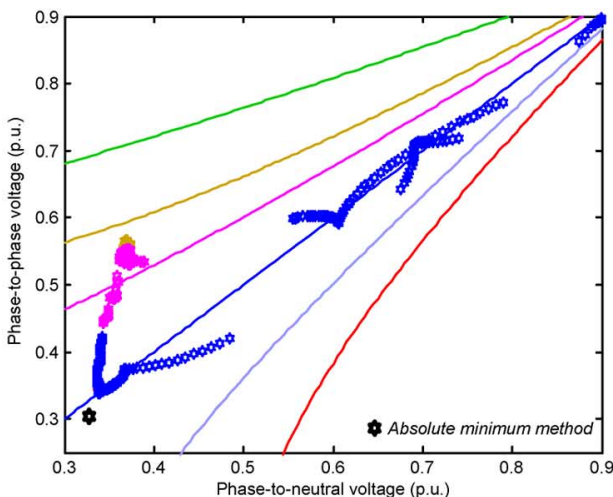

(d)

Fig. 7. Example (II). Characterization and comparison of methods. (a) Instantaneous voltage waveforms. (b) $V_{\mathrm{PP}}$ and $V_{\mathrm{PN}}$ evolution. (c) Region clustering. (d) Comparison of voltage dip classification.

line, both representatitve regions of each multistage voltage dip. Additionally, Fig. 11 shows a 3-D classification of the dip 


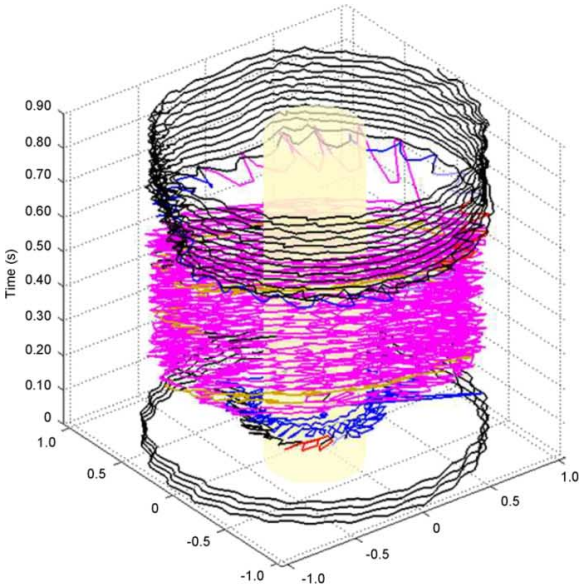

(a)

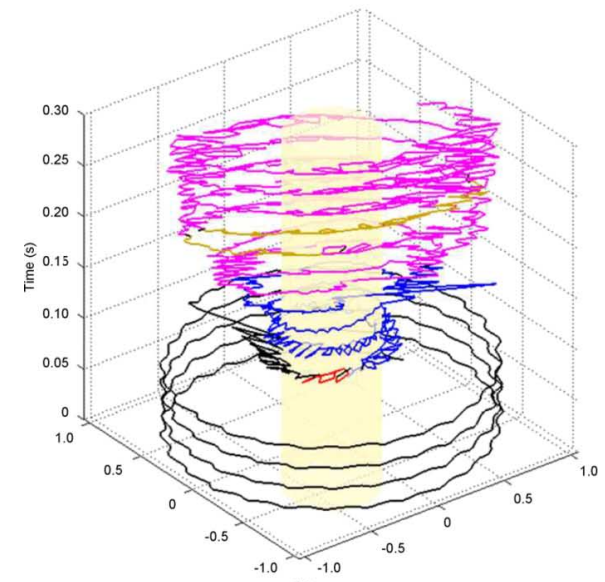

(b)

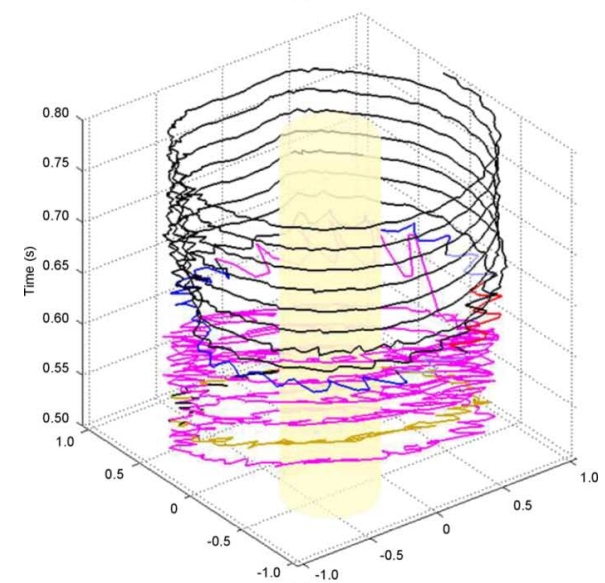

(c)

Fig. 8. Example (II). Cylindrical visualization of the voltage dip. (a) Voltage space vector evolution. (b) Voltage space vector. Beginning of the dip. (c) Voltage space vector. Ending of the dip.

duration and depth versus the number of events. In this way, it is presented as a traditional voltage-dip classification.

\section{CONCLUSION}

Voltage dips are a major concern in the wind energy industry, due to the requirement imposed by several national grid codes of uninterrupted generation throughout power system disturbances, such as voltage dips. This trend is constantly increasing as the share of wind farms in the generation mix becomes more relevant. With this in mind, a new voltage dip classification method is

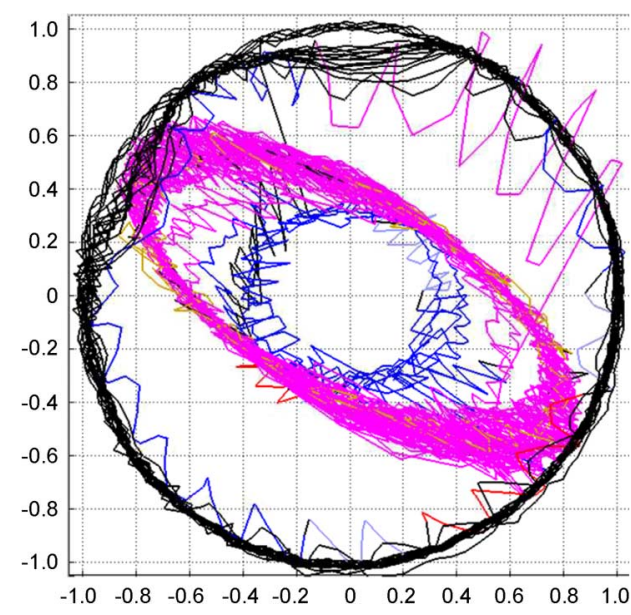

Fig. 9. Example (II). Polar visualization of the voltage dip.

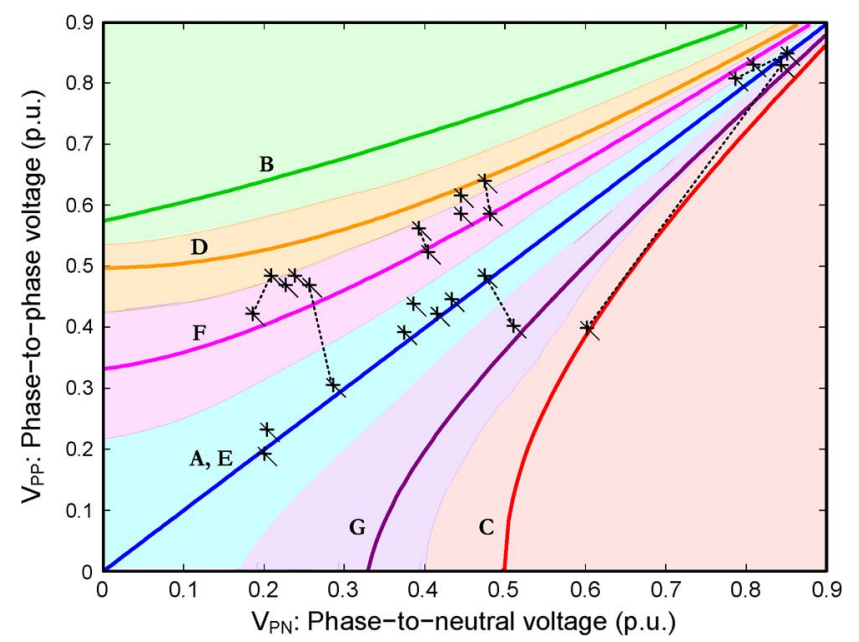

Fig. 10. Field measurement campaign. Voltage dip classification.

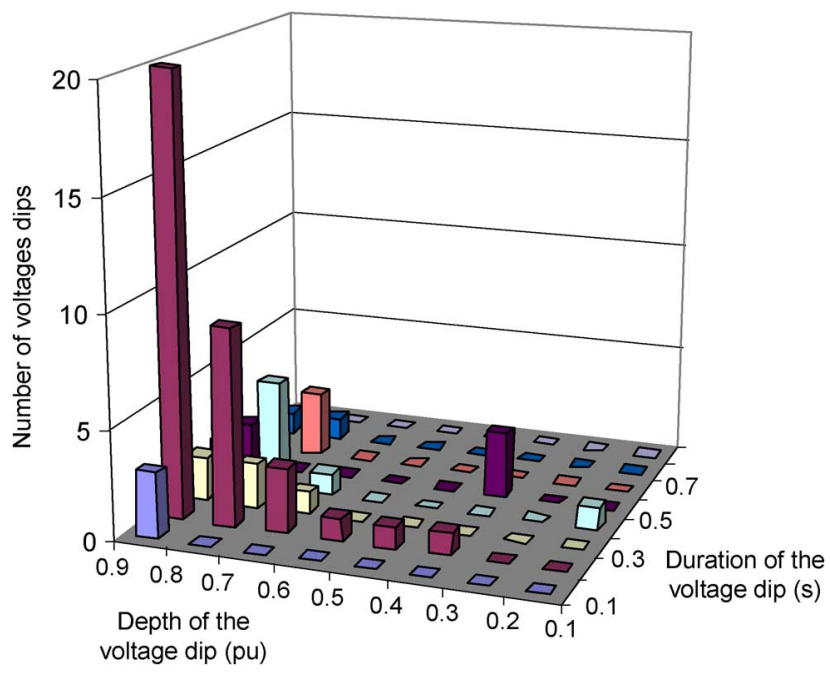

Fig. 11. Field measurement campaign. Depth-duration-frequency results.

proposed by the authors. This allows us to classify multistage and real voltage dips according to their evolution over time. An additional voltage dip visualization analysis is also proposed, taking into account the voltage space vector representation.

Information on different voltage dips collected by the authors as a result of the field measurement study in wind farms located 
in the Spanish region of Castilla-La Mancha has been used to assess this method. In this way, two examples of representative voltage dips are classified and the results are compared with previous methodologies. In addition, the classification of all measured voltage dips is presented and described by using the proposed method.

\section{ACKNOWLEDGMENT}

The authors would like to thank J. M. Abellán of "Dea y Energías Renovables" and the technicians of the Moralejo Wind Farm, Alpera, Albacete (Spain), as well as the Gamesa technicians.

\section{REFERENCES}

[1] C. Fitzer, M. Barnes, and P. Green, "Voltage sag detection technique for a dynamic voltage restorer," IEEE Trans. Ind. Appl., vol. 40, no. 1, pp. 203-212, Jan./Feb. 2004.

[2] Recommended Practices and Requirements for Harmonic Control in Electrical Power Systems, IEEE Std. 519-1992.

[3] D. J. Won, S. J. Ahn, and S. I. Moon, "A modified sag characterization using voltage tolerance curve for power quality diagnosis," IEEE Trans. Power Del., vol. 20, no. 4, pp. 2638-2643, Oct. 2005.

[4] I. Erlich and U. Bachmann, "Grid code requirements concerning connection and operation of wind turbines in germany," in Proc. IEEE Power Eng. Soc. General Meeting, San Francisco, CA, Jun. 2005, vol. 2, pp. 1253-1257.

[5] A. Dahlgren, C. Klippel, and A. Juntti, "Recorded fault ride through capability for two types of wind turbine generators," presented at the Nordic Wind Power Conf., Espoo, Finland, May 22-23, 2006.

[6] REE, "Operating procedure p.o.12.3. requisitos de respuesta frente a huecos de tensión de las instalaciones de producción de régimen especial," Red Eléctrica de España, Oct. 2006, Tech. Rep.

[7] E.ON, "Grid code high and extra high voltage," E.ON Netz GmbH, 2003, Tech. Rep. 2003.

[8] VDN, "Renewable energy sources connected to the high and extra high voltage network. guideline as attachment to the grid codes," Verband der Netzbetreiber, Aug. 2003, Tech. Rep.

[9] Federal Ministry for Environment, "Nature conversation and nuclear safety, act on granting priority to renewable energy sources (renewable energy sources act)." Federal Ministry for Environment, Berlin, Germany, Mar. 2000, Tech. Rep.

[10] M. F. McGranaghan, D. R. Mueller, and M. J. Samotyj, "Voltage sags in industrial systems," IEEE Trans. Ind. Appl., vol. 29, no. 2, pp. 391-403, Mar./Apr. 1993.

[11] M. H. J. Bollen, G. Olguin, and M. Martins, "Voltage dips at the terminals of wind power installations," Wind Energy, vol. 8, pp. 307-318, 2005.

[12] J. Wang, S. Chen, and T. T. Lie, "A systematic approach for evaluating economic impact of voltage dips," Elect. Power Syst. Res., vol. 77, pp. 145-154, 2006.

[13] Recommended Practice for Evaluating Electric Power System Compatibility With Electronic Process Equipment, IEEE Std. 1346-1998.

[14] C. Abbey and G. Joos, "Effect of low voltage ride through (lvrt) characteristic on voltage stability," in Proc. Power Eng. Soc. General Meeting, Jun. 2005, pp. 1901-1907.

[15] E. Gómez, J. A. Fuentes, A. Molina, F. Ruz, and F. Jiménez, "Results using different reactive power definitions for wind turbines submitted to voltage dips: Application to the spanish grid code," in Proc. IEEE Power Systems Conf. Expo, Oct./Nov. 2006, vol. 1, pp. 768-775.

[16] E. Gómez, J. Fuentes, A. Molina-Garcia, F. Ruz, and F. Jiménez, "Field tests of wind turbines submitted to real voltage dips under the new spanish grid code requirements," Wind Energy, vol. 10, no. 5, pp. 483-495, Jun. 2007.

[17] C. Jauch, J. Matevosyan, T. Ackermann, and S. Bolik, "International comparison of requirements for connection of wind turbines to power systems," Wind Energy, vol. 8, pp. 295-306, 2005.

[18] C. Jauch, P. Sorensen, and B. Bak-Jensen, "International review of grid connection requirements for wind turbines," presented at the Nordic Wind Power Conf., Goteborg, Sweden, Mar. 2004.

[19] J. Matevosyan, T. Ackermann, S. Bolik, and L. Söder, "Comparison of international regulations for connection of wind turbines to the network," presented at the Nordic Wind Power Conf., Goteborg, Sweden, Mar. 2004.
[20] M. H. J. Bollen, "Algorithms for characterizing measured three-phase unbalanced voltage dips," IEEE Trans. Power Del., vol. 18, no. 3, pp. 937-944, Jul. 2003.

[21] M. H. J. Bollen and L. D. Zhang, "Different methods for classification of three-phase unbalanced voltage dips due to faults," Elect. Power Syst. Res., vol. 66, pp. 59-69, 2003.

[22] L. Zhang and M. H. J. Bollen, "Characteristic of voltage dips (sags) in power systems," IEEE Trans. Power Del., vol. 15, no. 2, pp. 827-832, Apr. 2000.

[23] R. Leborgne and D. Karlsson, "Phasor based voltagge sag monitoring and characterization," in Proc. Int. Conf. Electricity Distribution, Jun. 2005, vol. 1, p. 105.

[24] S. Z. Djokic, J. V. Milanovic, D. J. Chapman, M. F. McGranaghan, and D. S. Kirschen, "A new method for classification and presentation of voltage reduction events," IEEE Trans. Power Del., vol. 20, no. 4, pp. 2576-2584, Oct. 2005.

[25] R. Leborgne, G. Olguin, and M. H. J. Bollen, "The influence of pq-monitor connection on voltage dip measurements," in Proc. Inst. Elect. Eng., MedPower Conf., Lemesos, Cyprus, Nov. 2004, vol. 1.

[26] M. H. J. Bollen, "Comparing voltage dip survey results," in Proc. Power Eng. Soc. Winter Meeting, 2002, vol. 2, pp. 1130-1134.

[27] Spanish Wind Energy Assoc. [Online]. Available: http://www.aeeolica.es

[28] C. Schauder and H. Mehta, "Vector analysis and control of advanced static var compensators," Proc. Inst. Elect. Eng. C, vol. 140, no. 4, pp. 299-306, Jul. 1993.

[29] E. Gómez-Lázaro, M. Cañas, J. A. Fuentes, and A. Molina-Garía, "Characterization of measured voltage dips in wind farms in the light of the new grid codes," in Powertech, Lausanne, Switzerland, Jul. 2007, vol. 1, pp. 2059-2064.

Emilio Gómez-Lázaro was born in Albacete, Spain, in 1969. He received the M.Sc. degree and Ph.D. degrees in electrical engineering from Valencia Technical University in 1995 and 2000, respectively.

Currently, he is an Associate Professor in the Department of Electrical, Electronics and Control Engineering at Castilla La Mancha University (UCLM), Albacete, Spain. He is the Director of the Renewable Energy Research Institute at UCLM. His research interests include modeling of the wind turbines and wind farms, grid codes, power system integration studies, steady-state and dynamic analysis, and maintenance of renewable energy power plants.

Juan Alvaro Fuentes was born in Murcia, Spain, in 1964. He received the Electrical Engineering degree from the Universidad de Zaragoza, Zaragoza, Spain, in 1994, and the Ph.D. degree in electrical engineering from the Universidad Politécnica de Cartagena, Cartagen, Spain, in 2001.

Currently, he is Associate Professor with the Electrical Engineering Department at the Universidad Politécnica de Cartagena, Cartagena, Spain. His research interests include wind power generation, load modeling, control, and optimization.

Angel Molina-García was born in Murcia, Spain, in 1973. He received the electrical engineering degree from the Universidad Politécnica de Valencia, Valencia, Spain, in 1998 and the Ph.D. degree in electrical engineering from the Universidad Politecnica de Cartagena, Cartagen, Spain, in 2003.

Currently, he is a Lecturer of Electrical Engineering with the Universidad Politecnica de Cartagena. His research interests include demand-side bidding, direct load control applications, load modeling, and wind power generation.

Miguel Cañas-Carretón was born in Ciudad Real, Spain, in 1980. He received the electrical engineering degree from the Universidad de Castilla-La Mancha, Albacete, Spain, in 2005 and is currently pursuing the $\mathrm{Ph} . \mathrm{D}$. degree in electrical engineering at the Universidad Politécnica de Cartagena, Cartagen, Spain.

Currently, he is with the Wind Energy Department of the Renewable Energy Research Institute of Universidad Castilla-La Mancha, Albacete. His research interests include the integration of renewable energy generation sources, development of wind turbine aggregated models, and the assessment of these models through real data. 